\title{
Formation Mechanism of Finished Surface in Ultrahigh-Speed Grinding with cubic Boron Nitride (cBN) Wheels*
}

\author{
Yoshio ICHIDA**, Ryunosuke SATO**, Yoshitaka MORIMOTO**, Yoshiteru OHSAWA** and \\ Nabil Ben FREDJ ${ }^{* * *}$
}

\begin{abstract}
In this paper, we describe the formation mechanism of a finished surface in ultrahighspeed grinding under a peripheral wheel speed higher than $200 \mathrm{~m} / \mathrm{s}$. Grinding experiments using a grinding machine tool equipped with an active magnetic bearing spindle have been conducted over a range of grinding speeds from 60 to $300 \mathrm{~m} / \mathrm{s}$. Moreover, grinding tests for producing some individual grooves using a grinding tool with multiple $\mathrm{cBN}$ grit have been carried out to clarify the effects of grinding speed on the side swelling formed along both sides of the grinding grooves. From the results of these experiments, we have confirmed that the roughness of the ground surface decreases with an increase in grinding speed, and this decrease is mainly due to the reduction of the swelling ratio with increasing grinding speed.
\end{abstract}

Key Words: Grinding, Abrasive Grain, Grinding Force, Ultrahigh-Speed Grinding, Electroplated cBN Grinding Wheel, Magnetic Bearing Spindle, Ground Surface, Side Swelling, Grinding Energy

\section{Introduction}

Ultrahigh-speed grinding is a powerful technique for achieving high productivity ${ }^{(1)}$. In particular, ultrahighspeed grinding with $\mathrm{cBN}$ abrasive grains is becoming widely used for high-efficiency machining, such as cam grinding in the field of automotive production ${ }^{(2)}$. Until now, many studies such as those on the development of the main spindle and the grinding wheel for ultrahighspeed grinding have been carried out ${ }^{(3)-(6)}$. However, the grinding mechanism in ultrahigh-speed grinding under a peripheral wheel speed higher than $200 \mathrm{~m} / \mathrm{s}$ is not yet sufficiently elucidated. For the purpose of enhancing the industrial use of ultrahigh-speed grinding, it is important to clarify the mechanism of material removal in ultrahighspeed grinding at speeds beyond $200 \mathrm{~m} / \mathrm{s}$.

The purpose of this study is to clarify the formation mechanism of a finished surface in ultrahigh-speed grinding under a peripheral wheel speed higher than $200 \mathrm{~m} / \mathrm{s}$. For this purpose, grinding experiments using a grinding machine equipped with an active magnetic bearing spin-

* Received 14th October, 2005 (No. 05-4209)

** Department of Mechanical Systems Engineering, Utsunomiya University, 7-2-1 Yoto, Utsunomiya, Tochigi 3218585, Japan. E-mail: ichida@cc.utsunomiya-u.ac.jp

*** Tunis Institute of Science \& Technology, 5 Avenue Taha Hussein, Tunis 1008, Tunisia dle are conducted over a range of grinding speed from 60 to $300 \mathrm{~m} / \mathrm{s}$. Moreover, basic grinding tests for producing individual grooves using a grinding tool with multiple cBN grit are carried out to clarify the effects of grinding speed on the side swelling ${ }^{(7)}$ formed along both sides of the ground groove, which will be directly related to the formation mechanism of the ground surface.

\section{Experimental Procedure}

\subsection{Surface grinding experiment}

Figure 1 shows a schematic view of the experimental setup. To provide high rotation speed for ultrahigh-speed grinding experiments, we used a grinding machine with an active magnetic bearing spindle. The maximum rotational

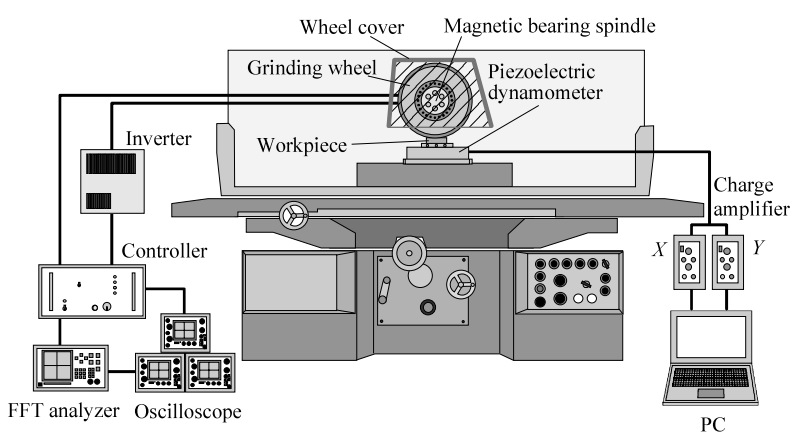

Fig. 1 Schematic view of experimental setup 
speed and output power are $55000 \mathrm{rpm}$ and $7.5 \mathrm{~kW}$, respectively. The performance specifications of the spindle are shown in Table 1. Electroplated cBN wheels having a hub and a flange that were integrally made of Ti alloy were used so as to prevent rotational fracture and vibration. Rotational stresses during ultrahigh-speed grinding can lead to failure if the wheel structure is not correctly designed. The design of the cBN wheel having the hub and the flange in one body was conducted on the basis of FEM analysis.

Experimental conditions are listed in Table 2. The maximum grain depth of cut $g_{\max }$ is given by

$$
g_{\max }=2 \lambda\left(v_{w} / v_{s}\right) \cdot \sqrt{a / d_{s}},
$$

where $v_{w}$ is the workpiece speed, $v_{s}$ is the peripheral wheel speed, $a$ is the wheel depth of cut, $d_{s}$ is the wheel diameter and $\lambda$ is the average successive cutting edge distance. In this experiment, the workpiece speed $v_{w}$ was increased in proportion to the increase of peripheral wheel speed to maintain the grain depth of cut $g_{\max }$ constant. cBN wheel was dressed with an impregnated diamond dresser under the following conditions: wheel speed $v_{s}=120 \mathrm{~m} / \mathrm{s}$, dressing lead $f_{d}=0.2 \mathrm{~mm} / \mathrm{rev}$., dressing depth $a_{d}=2 \mu \mathrm{m}$ $\times 2$ times.

Table 1 Performance specifications of magnetic bearing spindle

\begin{tabular}{|c|c|}
\hline Maximum rotation speed & $55,000 \mathrm{rpm}$ \\
\hline Continuous power & $6 \mathrm{~kW}$ \\
\hline $\begin{array}{lr}\text { Maximum radial load } & \text { Front } \\
& \text { Rear }\end{array}$ & $\begin{array}{l}300 \mathrm{~N} \\
150 \mathrm{~N}\end{array}$ \\
\hline Maximum axial load & $300 \mathrm{~N}$ \\
\hline Dimensions & $\phi 240 \times l 413 \mathrm{~mm}$ \\
\hline
\end{tabular}

\subsection{Grinding test using multiple cutting edges}

In order to grasp the effects of wheel speed on the formation mechanism of the finished surface, grinding tests using multiple cutting edges were carried out, as shown in Fig. 2. Several cBN grains are fixed on a grit holder by electroplating. This multipoint grinding tool is attached to the peripheral surface of a high-strength aluminum alloy disk. Using the rotation of this grinding tool that has multiple cBN cutting edges, some individual grooves (streaks) are produced on the smoothly finished workpiece surface. In this case, because the successive cutting edge distance $\lambda$ is $\pi d_{s}$, the workpiece speed is increased in proportion to the increase of wheel speed under a constant condition of $g_{\max }=1 \mu \mathrm{m}$. Experimental conditions for the grinding tests using multiple cutting edges are listed in Table 3.

\section{Experimental Results}

\subsection{Effects of wheel speed on the surface roughness}

Figure 3 shows the effect of grinding speed on the roughness of the ground surface in the range of periph-

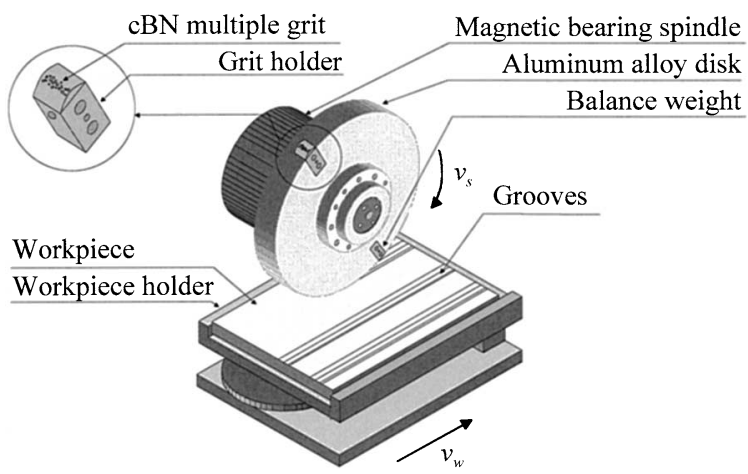

Fig. 2 Experimental setup for grinding tests using multiple cutting edges

Table 2 Experimental conditions for ultrahigh-speed grinding

\begin{tabular}{|c|c|c|c|c|c|c|c|c|c|c|}
\hline Grinding method & & \multicolumn{9}{|c|}{ Dry surface grinding, Up-cut } \\
\hline Grinding wheel & & \multicolumn{9}{|c|}{$\begin{array}{l}\text { cBN140N100P } \\
\text { Dimensions: } \phi 150 \times t 10 \mathrm{~mm}\end{array}$} \\
\hline Wheel depth of cut & $a$ & \multicolumn{9}{|c|}{$30 \mu \mathrm{m}$} \\
\hline Peripheral wheel speed & $v_{s}$ & 60 & 180 & 200 & 220 & 240 & 260 & 280 & 300 & $\mathrm{~m} / \mathrm{s}$ \\
\hline Work speed & $v_{w}$ & 0.05 & 0.15 & 0.167 & 0.183 & 0.2 & 0.217 & 0.233 & 0.25 & $\mathrm{~m} / \mathrm{s}$ \\
\hline Stock removal rate & $Z^{\prime}$ & 1.5 & 4.5 & 5.0 & 5.5 & 6.0 & 6.5 & 7.0 & 7.5 & $\mathrm{~mm}^{3} / \mathrm{mm} \cdot \mathrm{s}$ \\
\hline Speed ratio & $v_{w} / v_{s}$ & \multicolumn{9}{|c|}{$0.83 \times 10^{-3}$} \\
\hline Workpiece & & \multicolumn{9}{|c|}{$\begin{array}{l}\text { Bearing steel JIS SUJ2 (HRC62) } \\
\text { Dimensions: } 30^{l} \times 5^{t} \times 25^{h} \mathrm{~mm}\end{array}$} \\
\hline
\end{tabular}

Table 3 Experimental conditions for grinding test using multiple cutting edges

\begin{tabular}{lc|c|c|c|c|c|c|c}
\hline Grinding method & \multicolumn{6}{|c}{ Dry surface grinding, Up-cut } \\
\hline Grit type & \multicolumn{6}{c}{ cBN (Grain size: \#60/80) } \\
\hline Peripheral wheel speed & $v_{s}$ & 60 & 120 & 180 & 200 & 220 & 240 & $260 \mathrm{~m} / \mathrm{s}$ \\
\hline Work speed & $v_{w}$ & 3.84 & 7.68 & 11.5 & 12.8 & 14.1 & 15.4 & $16.6 \mathrm{~mm} / \mathrm{s}$ \\
\hline Depth of cut & $a$ & $30 \mu \mathrm{m}$ \\
\hline Workpiece & \multicolumn{8}{|l}{ Bearing steel JIS SUJ2 (HRC62) } \\
& Dimensions: $15^{l} \times 30^{t} \times 5^{h} \mathrm{~mm}$ \\
\hline
\end{tabular}


eral wheel speed from 60 to $300 \mathrm{~m} / \mathrm{s}$. Both the maximum height of profile $R z$ and the arithmetical mean deviation of the assessed profile $R a$ decrease with an increase in peripheral wheel speed. The roughness at wheel speeds higher than $200 \mathrm{~m} / \mathrm{s}$ decreases by 20-30\% compared with that at the conventional wheel speed of $60 \mathrm{~m} / \mathrm{s}$.

In order to investigate the reason for the decreasing surface roughness, we have observed the ground surface with a scanning electron microscope (SEM) equipped with multiple probes. Figure 4 shows representative results of the SEM images and the 3-dimensional profiles. Many large swellings along the grinding streaks are observed in the surface ground at the conventional speed of $60 \mathrm{~m} / \mathrm{s}$. These swellings are fundamentally formed because of plastic deformation caused along both sides of the groove by the action of the grain cutting edge and are generally called side swelling or swell-out residual ${ }^{(7)}$. From the changes of these 3-D profiles shown in Fig. 4, it is understood that the side swelling decreases with increasing wheel speed. This result reveals that the decrease of surface roughness with an increase in wheel speed is closely related to the decrease of the side swelling with increasing wheel speed.

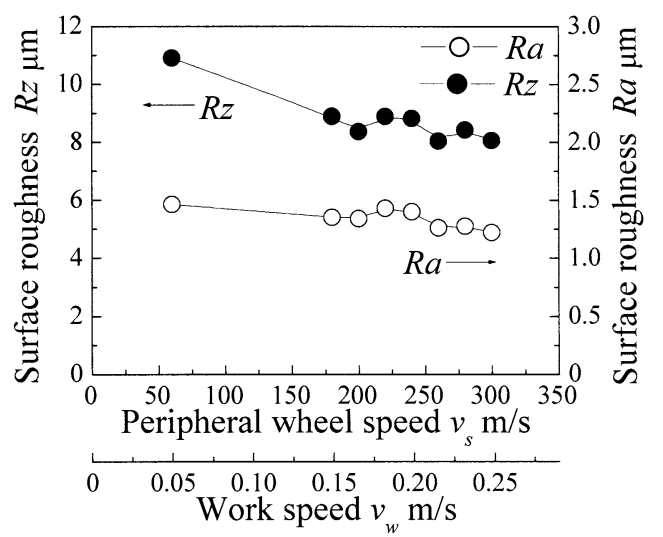

Fig. 3 Effect of grinding speed on roughness of ground surface
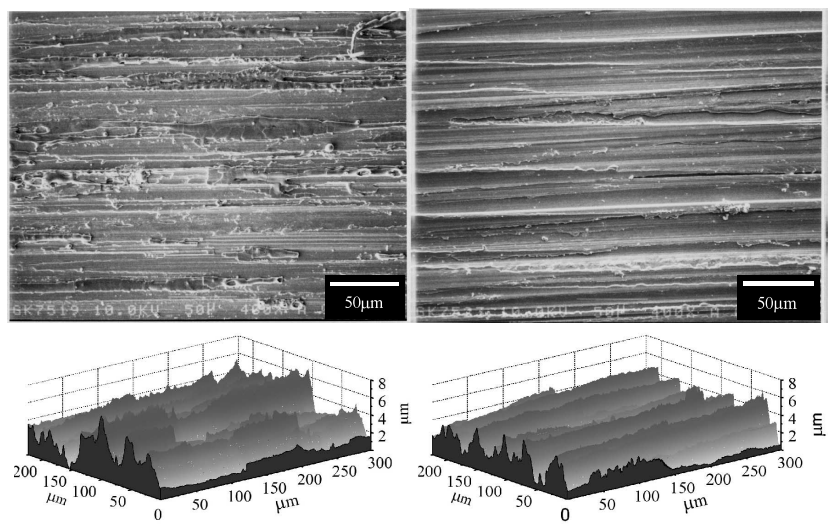

(a) $v_{s}=60 \mathrm{~m} / \mathrm{s}$
Accordingly, we have evaluated the surface profile using a bearing curve to clarify the relationship between the surface roughness and the side swelling. The bearing curve is widely used in the characterization of engineering surfaces. It is particularly effective for evaluating the sharpness of peaks of profile curves. Figure 5 shows typical examples of bearing curves calculated from 3-D profiles of ground surfaces. The bearing curve in the case of the conventional speed of $60 \mathrm{~m} / \mathrm{s}$ is on the leftmost side. This means that the profile curve consists of sharp peaks attributed to the side swelling. However, the bearing curve is successively shifted to the right with increasing wheel speed. That is, the sharp peaks of the profile curve become successively blunt with increasing wheel speed. This suggests that the reduction of surface roughness is mainly due to the reduction of the swell-out residual formed along both sides of grinding streaks.

\subsection{Effects of wheel speed on side swelling}

The relationship between the surface roughness and the side swelling described above has been concretely investigated on the basis of the results of the grinding test using multiple cutting edges. Figure 6 shows the typical SEM images of the grooves generated at wheel speeds of

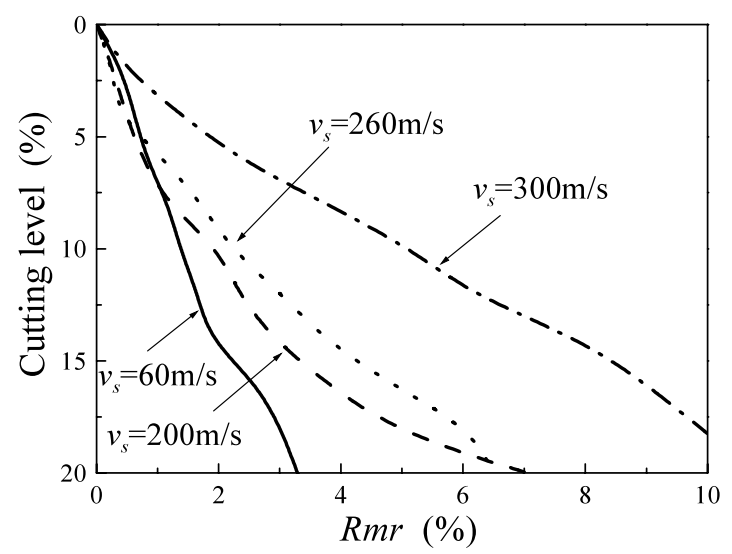

Fig. 5 Bearing curves calculated from 3-D profile of ground surface
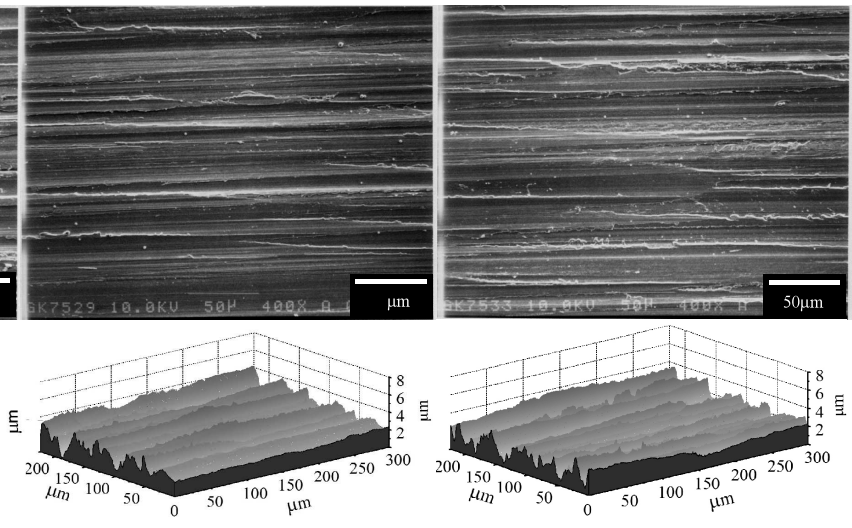

(c) $v_{s}=260 \mathrm{~m} / \mathrm{s}$

(a) $v_{s}=300 \mathrm{~m} / \mathrm{s}$

Fig. 4 SEM images and 3-dimensional profiles of ground surfaces 


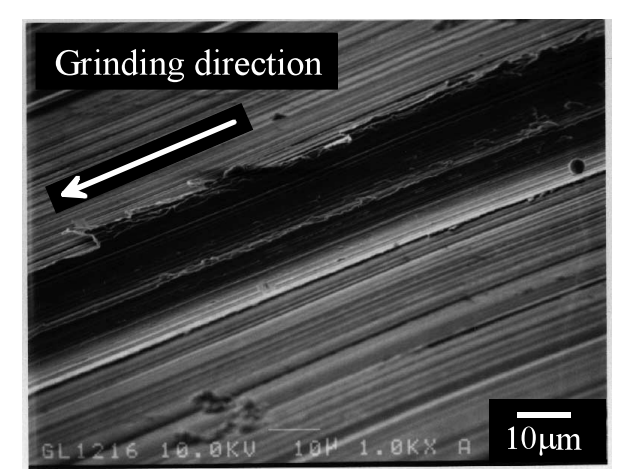

(a) $v_{s}=60 \mathrm{~m} / \mathrm{s}$

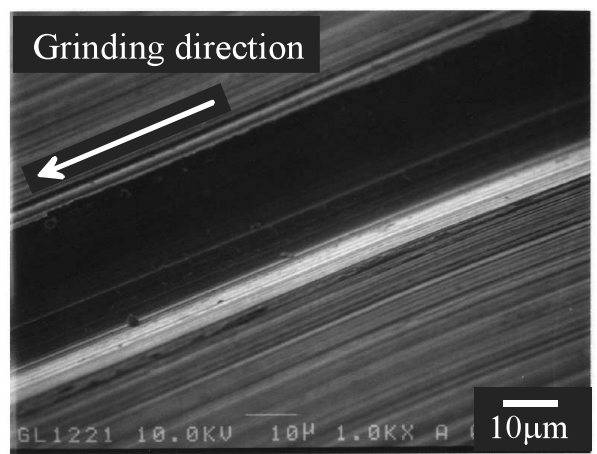

(c) $v_{s}=220 \mathrm{~m} / \mathrm{s}$

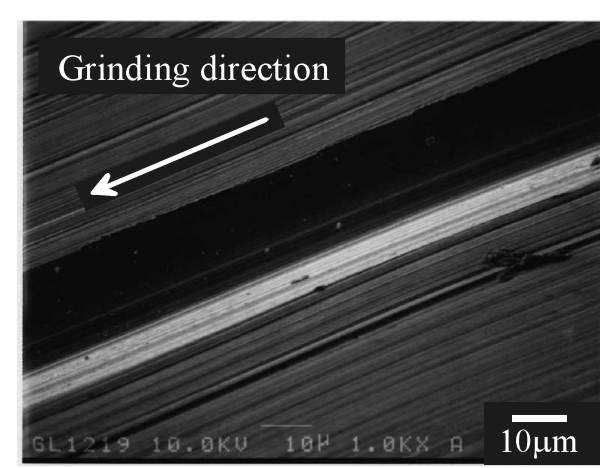

(b) $v_{s}=180 \mathrm{~m} / \mathrm{s}$

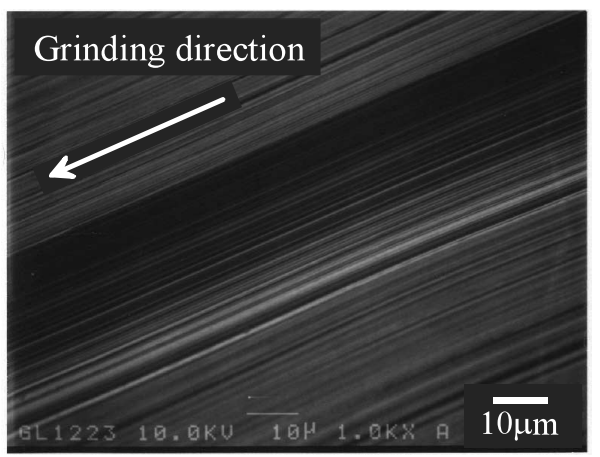

(d) $v_{s}=260 \mathrm{~m} / \mathrm{s}$

Fig. 6 Typical SEM images of grinding grooves formed at wheel speeds of 60, 180, 220 and $260 \mathrm{~m} / \mathrm{s}$

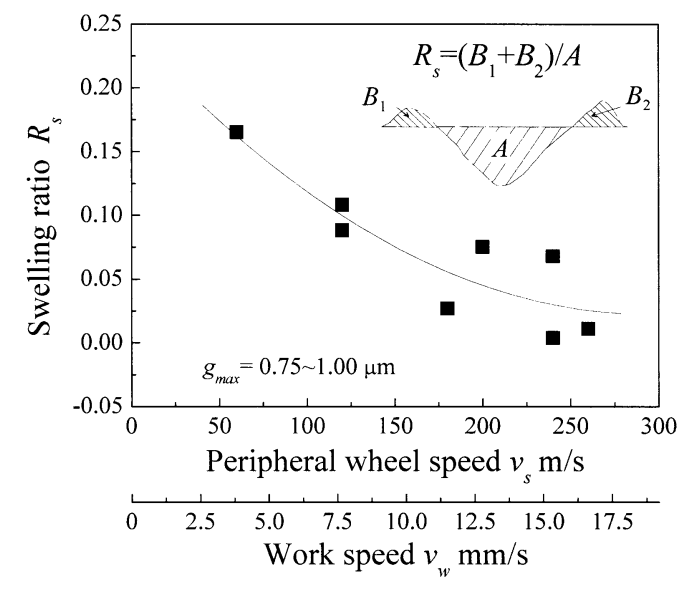

Fig. 7 Relationship between swelling ratio and wheel speed

60, 180, 220 and $260 \mathrm{~m} / \mathrm{s}$. Large side swelling is formed along both sides of grooves ground at the conventional speed of $60 \mathrm{~m} / \mathrm{s}$. However, the side swelling becomes smaller with increasing grinding speed. In order to evaluate quantitatively the relationship between side swelling and grinding speed, the swelling ratio $R_{s}=A /\left(B_{1}+B_{2}\right)$, that is, the ratio of the cross-sectional area of the groove $A$ to the total cross-sectional area of the side swelling $\left(B_{1}+B_{2}\right)$, was obtained from the cross-sectional profile curve of the groove, as shown in Fig. 7. With increasing grinding speed, the swelling ratio decreases and becomes very small at speeds higher than $200 \mathrm{~m} / \mathrm{s}$. This re- sult agrees with the above-described result of evaluating the bearing curve.

\subsection{Effects of wheel speed on grinding forces and grinding energy}

To consider the mechanism of surface formation from the viewpoint of grinding energy, grinding force components have been measured under a constant speed ratio over a speed range from 60 to $300 \mathrm{~m} / \mathrm{s}$. Figure 8 shows the changes of the normal force, the tangential force and the ratio of force components with increasing wheel speed. With increasing speed, the normal force increases slightly, but the tangential force decreases. Consequently, the ratio of force components $F_{t} / F_{n}$ decreases. This result can be illustrated as shown in Fig. 9. Namely, both angle $\theta$ and absolute value, in a vector diagram, of resultant grinding force $R$ at speeds higher than $200 \mathrm{~m} / \mathrm{s}$ are smaller than those at the conventional speed of $60 \mathrm{~m} / \mathrm{s}$.

Figure 10 shows the specific grinding energy calculated from the tangential grinding force. The specific grinding energy decreases with increasing wheel speed. The grinding energy at speeds higher than $200 \mathrm{~m} / \mathrm{s}$ is reduced by $20-30 \%$ compared with that at the wheel speed of $60 \mathrm{~m} / \mathrm{s}$. This result is closely related to the abovedescribed reduction of side swelling with increasing wheel speed. 


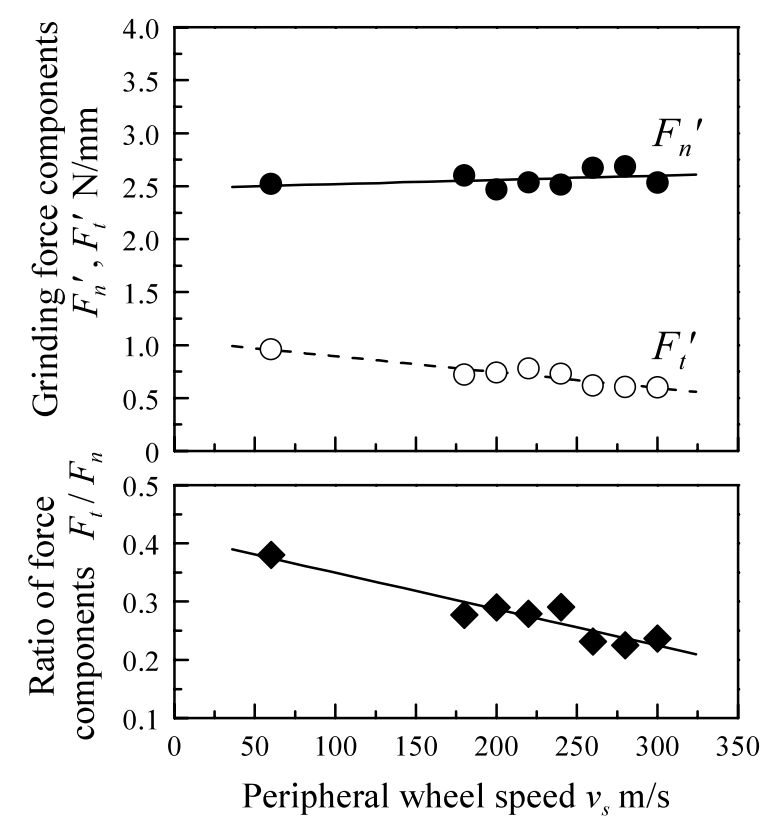

Fig. 8 Effects of grinding speed on normal force, tangential force and ratio of force components

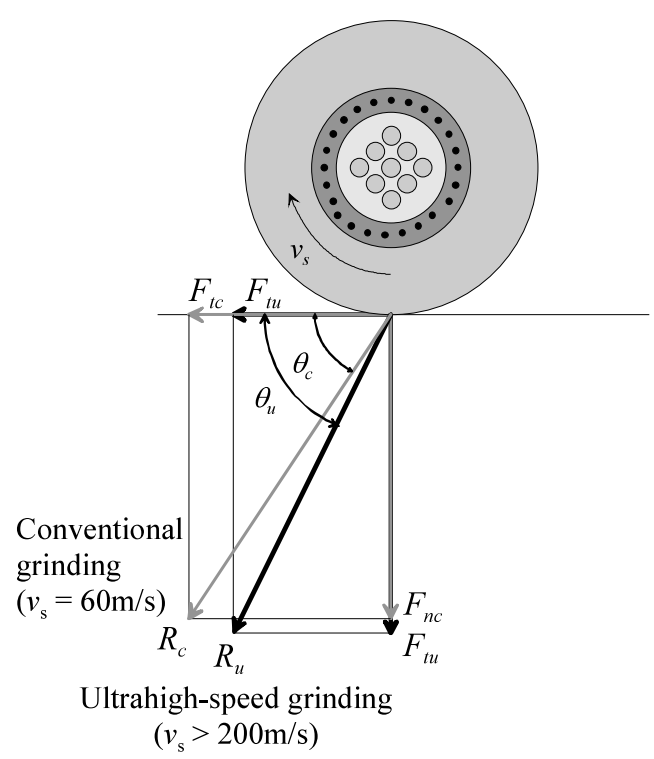

Fig. 9 Difference in grinding force vector between conventional and ultrahigh-speed grindings

\section{Discussion}

To consider the mechanism of surface generation from the standpoint of the material removal process, the morphology of grinding chips was observed with SEM. Typical SEM images of the chips are shown in Fig. 11. Because of dry grinding, many melted chips are observed. However, grinding chips that are not melted are also observed. These results confirm that the chip thickness decreases and the chip becomes longer with increasing grinding speed. This result indicates that the shear angle increases and the shear strain in the shear zone decreases

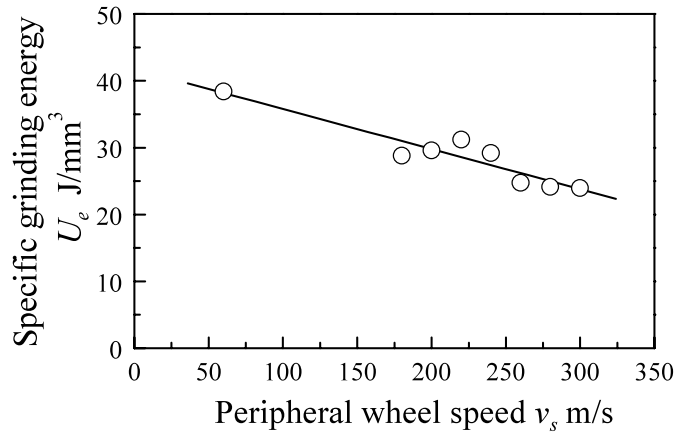

Fig. 10 Effect of grinding speed on specific grinding energy

with increasing wheel speed. On the basis of these results, the differences in formation mechanisms of the chip and the finished surface under conventional grinding and under ultrahigh-speed grinding can be illustrated as shown in Fig. 12.

Increasing the peripheral wheel speed has the following effects.

(1) The chip thickness decreases and the chip length increases.

(2) Therefore, the shear angle $\Phi_{c}$ increases and the shear strain in the shear zone decreases.

( 3 ) Because the shear strain rate increases, the shear zone becomes smaller and then the area of stress distribution becomes smaller ${ }^{(7)}$.

(4) Consequently, the side swelling formed along both sides of a groove as well, as the plastic flow zone formed just under the groove surface, becomes smaller. At the same time, specific grinding energy also decreases.

Thus, various changes in the material removal mechanism during grinding are induced upon increasing the wheel speed. These changes lead to the good results of decreased surface roughness, tangential grinding force and specific grinding energy.

\section{Conclusions}

Ultrahigh-speed grinding experiments using a grinding machine equipped with an active magnetic bearing spindle have been conducted over a range of grinding speeds from 60 to $300 \mathrm{~m} / \mathrm{s}$. The main results obtained in this study are summarized as follows.

(1) As the peripheral wheel speed increases, the roughness of the ground surface decreases. This reduction of the surface roughness is mainly due to the reduction of the side swelling formed along both sides of the groove with increasing grinding speed.

( 2 ) As the peripheral wheel speed increases, the normal grinding force increases slightly, but the tangential grinding force decreases. Consequently, the ratio of force components decreases with increasing grinding speed.

( 3 ) The specific grinding energy decreases with increasing grinding speed. The grinding energy at a wheel 


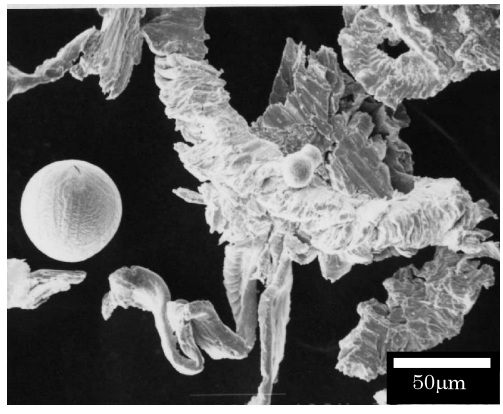

(a) $v_{s}=60 \mathrm{~m} / \mathrm{s}$

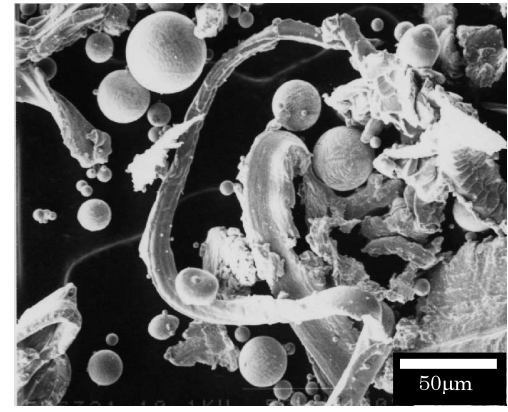

(b) $v_{s}=220 \mathrm{~m} / \mathrm{s}$

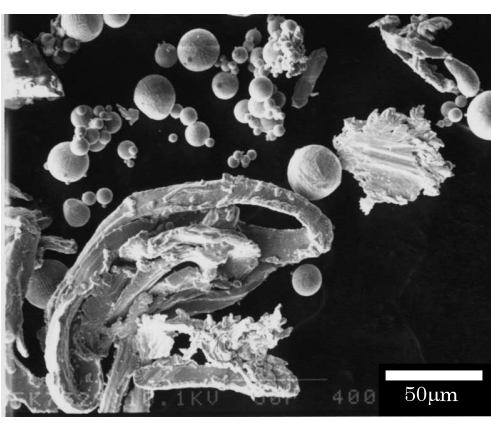

(c) $v_{s}=300 \mathrm{~m} / \mathrm{s}$

Fig. 11 Effect of grinding speed on shape of grinding chips

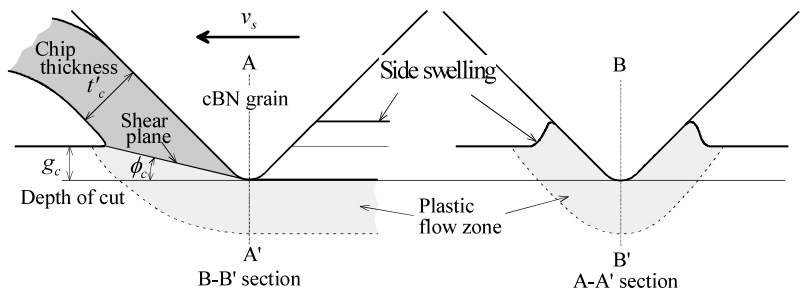

(a) Conventional grinding $\left(v_{s}=60 \mathrm{~m} / \mathrm{s}\right)$

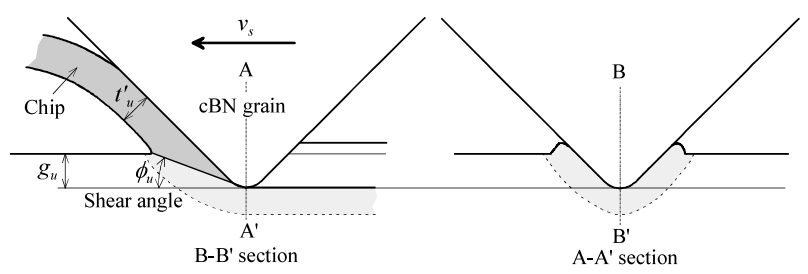

(b) Ultrahigh-speed grinding $\left(v_{s}>200 \mathrm{~m} / \mathrm{s}\right)$

Fig. 12 Difference in material removal mechanism between conventional and ultrahigh-speed grindings $\left(g_{c}=g_{u}\right)$

speed higher than $200 \mathrm{~m} / \mathrm{s}$ is reduced by $20-30 \%$ compared with that at the conventional wheel speed of $60 \mathrm{~m} / \mathrm{s}$.

\section{References}

( 1 ) Opitz, H. and Guhring, K., High Speed Grinding, Annals of the CIRP, Vol.16, No.2 (1968), pp.61-64.
( 2 ) Wakuda, M., Ota, M., Ueda, H. and Miyahara, K., Development of Ultrahigh Speed and High Power Cam Grinding Machine (1st Report) - Characteristics of Ultrahigh Speed Grinding of Chilled Casting-, J. Jpn. Soc. Prec. Eng., (in Japanese), Vol.64, No.4 (1998), pp.593-597.

( 3 ) Webster, J.A., Design of a $250 \mathrm{~m} / \mathrm{s}$ CBN Grinding Machine, 4th International Grinding Conference, (1990), MR90-551.

( 4 ) Konig, W. and Ferlemann, F., A New Dimension for High-Speed Grinding, Ind. Diamond Rev., Vol.51, No.546 (1991), pp.237-243.

( 5 ) Inada, Y., Syoji, K., Kuriyagawa, T. and Unno, K., Development of Wheel Spindle for Ultra-High Speed Surface Grinding Machine-Studies on Ultra-High Speed Grinding (1st Report)—, J. Jpn. Soc. Prec. Eng., (in Japanese), Vol.62, No.4 (1996), pp.569-573.

( 6 ) Fredj, N.B., Ichida, Y. and Kishi, K., Formation of Grinding Streaks by a Single Diamond Abrasive Grain in Ultra-High Speed Grinding, Jpn. Soc. Prec. Eng. Publication Series, No.1 (1994), pp.485-490.

( 7 ) Okoshi, M., Yoshikawa, H. and Sata, T., Speed-Effect on Swell-Out Residual in Single Grinding, J. Jpn. Soc. Prec. Eng., (in Japanese), Vol.25, No.10 (1959), pp.524-530. 